\title{
Oral Health Status among Drug Addicts in a Selected Hospital in Dhaka City
}

\author{
MAA Mamun', MJ Kabir², MSA Farzan ${ }^{3}$, I Zerin ${ }^{4}$, MA Kabir ${ }^{5}$, AKMS Uddin ${ }^{6}$
}

\begin{abstract}
This was a cross-sectional study on oral health status of drug addicted patients admitted in a drug abuse treatment center in Dhaka city. This study was conducted at Mukti Mental Hospital, Drug \& Alcohol Treatment Center situated at Gulshan, Dhaka, Bangladesh. The study was carried out among 50 drug addicts from the month of January to June 2012. Data were collected from the patients from 21st April to 5th May 2012. The main objective of the study was to assess and investigate the oral hygiene practice and oral health status of drug abusers. Fifty drug abusers irrespective of sex and age were interviewed \& their oral health status was evaluated using the World Health Organization recommended procedures for Decayed, Missing, Filled teeth and the periodontal status. Data were collected with a pretested structured questionnaire and checklist. Dental caries was found in $92 \%$ of the drug addicts, while Missing and Filled teeth were recorded $86 \%$ and $88 \%$ of the addicts respectively. $86 \%$ of the addicts demonstrated DMFT score 1 or Higher; whereas 14\% of the addicts demonstrated DMFT score 0 or were free from any form of dental decay, missing teeth or dental filling and $74 \%$ of the drug addicts had gingival inflammation and bleeding from gum, 42\% had some oral mucosal lesion like apthus ulcer and candidiasis. The number of Decayed, Missing or Filled teeth increased with less frequency of daily tooth brushing and this finding was significant $(p<0.01)$. On the basis of these findings it was concluded that dental caries in drug addicts is a major health concern and creating awareness among the public about harmful effects of drugs on their oral health through plan and policy can reduce the burden of dental diseases. Moreover mass media and general education of the mass people can play a vital role.
\end{abstract}

Keywords: Oral health status, Drug addicts.

\section{Introduction}

A public health approach to drug addiction should include preventing initiation of use, facilitating addiction cessation, and promoting abstinence from all kinds of drug by current users.

1. Dr. Md. Abdullah Al Mamun, BDS, MPH, Assistant Professor, Department of Oral Pathology, Pioneer Dental College \& Hospital, Dhaka, Bangladesh.

2. Dr. Md. Jahangir Kabir, BDS, FICD, FADI, Vice Principal, Pioneer Dental College and Hospital, Dhaka, Bangladesh.

3. Dr. Md. Sajedul Asif Farzan, BDS.MPH, Assistant Professor, Department of Pediatric Dentistry, Pioneer Dental College \& Hospital, Dhaka, Bangladesh.

4. Dr. Ishrat Zerin, BDS, MPH, Assistant Professor and Head, Department of Pediatric Dentistry, Saphena Womens Dental College \& Hospital, Dhaka, Bangladesh.

5. Dr. Md. Arafat Kabir, BDS, Fellow-Ph.D (Japan),, Founder Director and Lecturer, Dept of Oral and Maxillofacial Surgery, Pioneer Dental College, Dhaka, Bangldesh.

6. Dr. A. K. M Salah Uddin, BDS, MDS, Assistant Professor and Head, Department of Science of Dental Materials, Chattagram International Dental College \& Hospital, Chittagong, Bangladesh.

\section{Address of Correspondence:}

Dr. Md. Abdullah Al Mamun, BDS, MPH, Assistant Professor, Department of Oral Pathology, Pioneer Dental College \& Hospital, Dhaka, Bangladesh, E-mail: abdullah.mamun7419@gmail.com
Addiction is a chronic, relapsing disorder characterized by compulsion to take a drug and loss of self-control in limiting drug intake. ${ }^{1}$

The substances or drugs may be natural or synthetic, the use of which has a psychoactive effect and alters or modifies the functions of a living organism. Globally, the number of drug abusers in 2007 was 200 million, i.e. $4.8 \%$ of the global population. ${ }^{2}$ In the latest reports with regards to Indian context, 11.35 million persons were addicted to drugs. ${ }^{3}$ In Bangladesh the number of drug abusers is about 2 millions.

Drugs commonly abused are narcotics (including poppy, opium, morphine, codeine, heroin, brown sugar, opioids, meperidine, pethidine, and methadone), cannabis (marijuana, hashish, and dried parts of cannabis plant), stimulants (amphetamines, cocaine), hallucinogens (LSD, phencyclidine, mescaline, and psilocybin), depressants (barbiturates and benzodiazepines), and miscellaneous (antihistaminics, solvents in aerosols, glue, and whitening fluid). ${ }^{4}$ In Bangladesh gull, sada pata, jorda, guzza, phensidil, yaba,bangla mod has been traditionally known. In India, the abuse of alcohol, cannabis, and raw opium has been traditionally known; while the abuse of synthetic narcotic drugs and psychotropic substances is comparatively a new phenomenon. ${ }^{4}$ 
Studies have shown that the dental health and oral health are affected by drug abuse. ${ }^{5-9}$ Concomitant use of psychotropic substances such as tobacco, alcohol and areca nut further deteriorates the health status of the individual. Drugs abused adversely affect the oral soft and hard tissues (dental caries, periodontitis) or may lead to potentially malignant states (leukoplakia, oral submucous fibrosis) or may predispose to oral infections (candidiasis, gingivitis) by compromising local immunity. ${ }^{10}$ Description of the oral health status of drug addicts in Bangladeshi drug abuse treatment centers need sparse, a cross sectional study was performed to ascertain the status of oral health among drug addicts.

\section{Materials and Methods}

This study was a cross-sectional study. The study was carried out at Mukti Madokashokti Niramoy Kendro at Gulshan-2, Dhaka, Bangladesh. Total allocated study period was 6 months commencing from January to June 2012. 50 addicted patients irrespective of age and sex admitted at the centre were selected for the study. Purposive sampling technique was used.

Data were collected by the researcher himself through observation; interview of the addicted patients and by clinical examination of the oral cavity after taking verbal consent of the patients.

Data analysis was done using statistical software Statistical Package for Social Science or SPSS for Windows version and Microsoft Excel according to the key variables and objectives of the study.

\section{Results}

Table 1: Distribution of the addicts according to occurrence of bleeding from gum during tooth brushing $(n=50)$

\begin{tabular}{|c|c|c|}
\hline Occurrence of bleeding from gum & Frequency & Percentage \\
\hline Yes & 37 & 74 \\
No & 13 & 26 \\
Total & 50 & 100 \\
\hline
\end{tabular}

Table 1- shows that majority of drug addicts $37(74 \%)$ had bleeding from gum, while $13(26 \%)$ drug addicts had no bleeding.

Table 2: Distribution of the drug addicts by the number of decayed teeth $(n=50)$

\begin{tabular}{|c|c|c|}
\hline Number of decayed teeth & Frequency & Percentage \\
\hline None & 5 & 10 \\
1 & 7 & 14 \\
2 & 5 & 10 \\
3 & 11 & 22 \\
4 & 9 & 18 \\
$>4$ & 13 & 26 \\
Total & 50 & 100 \\
\hline
\end{tabular}

Table 2- shows that among drug addicts $10 \%$ had decayed free teeth, $7(14 . \%)$ had only 1 tooth decay, $5(10 \%)$ had 2 teeth decay, $11(22 \%)$ had 3 teeth decay, $9(18 \%)$ had 4 teeth decay, while $13(26 \%)$ had more than 4 teeth decayed.

Table 3: Distribution of the drug addicts by oral mucosal lesion $(\mathrm{n}=50)$

\begin{tabular}{|c|c|c|}
\hline Presence of oral mucosal lesion & Frequency & Percentage \\
\hline Yes & 21 & 42 \\
No & 29 & 58 \\
Total & 50 & 100 \\
\hline
\end{tabular}

Table 3- shows that among drug addicts 21(42\%) had oral mucosal lesion, while $29(58 \%)$ had no any oral mucosal lesion.

Table 4: Distribution of the drug addicts by gingival inflammation $(n=50)$

\begin{tabular}{|c|c|c|}
\hline Presence of gingival inflammation & Frequency & Percentage \\
\hline Yes & 37 & 74 \\
No & 13 & 26 \\
Total & 50 & 100 \\
\hline
\end{tabular}

Table 4- Shows that among drug addicts 37 (74\%) had gingival inflammation, while $13(26 \%)$ did not have any gingival inflammation

Table 5: Distribution of drug addicts by the number of missing teeth $(n=50)$

\begin{tabular}{|c|c|c|}
\hline Number of missing teeth & Frequency & Percentage \\
\hline None & 7 & 14 \\
$\mathbf{1}$ & 12 & 24 \\
$\mathbf{2}$ & 5 & 10 \\
$\mathbf{3}$ & 9 & 18 \\
$\mathbf{4}$ & 17 & 34 \\
Total & 50 & 100 \\
\hline
\end{tabular}

Table 5- shows that among drug addicts 7 (14\%) did not have any missing tooth, $12(24 \%)$ had only 1 tooth missing, 5(10\%) had 2 teeth missing, $9(18 \%)$ had 3 teeth missing, 17(34\%) had 4 teeth missing

Table 6: Distribution of drug addicts by the number of filled teeth $(n=50)$

\begin{tabular}{|c|c|c|}
\hline Number of filled teeth & Frequency & Percentage \\
\hline None & 6 & 12 \\
$\mathbf{1}$ & 13 & 26 \\
$\mathbf{2}$ & 8 & 16 \\
$\mathbf{3}$ & 11 & 22 \\
$\mathbf{4}$ & 12 & 24 \\
\hline
\end{tabular}


Table 6- shows that among 50 addicts $6(12 \%)$ did not have any filled tooth, $23(46 \%)$ had only 1 tooth filled, $8(16 \%)$ had 2 teeth filled, $11(22 \%)$ had 3 teeth filled, $12(24 \%)$ had 4 teeth filled.

Table 7: Distribution of the drug addicts according to DMFT score $(\mathbf{n}=\mathbf{5 0})$

\begin{tabular}{|c|c|c|}
\hline DMFT score & Frequency & Percentage \\
\hline $\mathbf{0}$ & 7 & 14 \\
& & \\
T>1 & 43 & 86 \\
Total & 50 & 100 \\
\hline
\end{tabular}

Table 7 - shows that among drug addicts 7 (14\%) had DMFT score 0 , while $43(86 \%)$ had DMFT score 1 or above.

\section{Discussion}

While several studies reported regarding dental diseases and oral hygiene practice in Bangladesh population, there is no documented information about drug abusers' oral health status. This paper therefore, provides background information on the status of oral health among a group of drug abusers undergoing rehabilitation at a major narcotic detoxification center in Bangladesh. Fifty drug abusers irrespective of sex and age were interviewed $\&$ their oral health status was evaluated using the World Health Organization recommended procedures for Decayed, Missing, Filled teeth and the periodontal status and by oral mucosal lesion \& gingival inflammation. Data were collected with a pretested structured questionnaire and checklist. Dental caries was found in $92 \%$ of the drug addicts, while Missing and Filled teeth were recorded $86 \%$ and $88 \%$ of the addicts respectively. $86 \%$ of the addicts demonstrated DMFT score 1 or Higher; whereas $14 \%$ of the addicts demonstrated DMFT score 0 or were free from any form of dental decay, missing teeth or dental filling and $74 \%$ of the drug addicts had gingival inflammation and bleeding from gum, $42 \%$ had some oral mucosal lesion like apthus ulcer and candidiasis. The number of Decayed, Missing or Filled teeth increased with less frequency of daily tooth brushing and this finding was significant $(p<0.01)$. On the basis of these findings it was concluded that dental caries in drug addicts is a major health concern and creating awareness among the public about harmful effects of drugs on their oral health through plan and policy can reduce the burden of dental diseases.

\section{Conclusion}

This study found an increase in the rate of caries with increasing duration and frequency of using drugs. Male seems to suffer more from dental decay in comparison to female because number of addicts in male are more than female. The overall oral health status of addicts was not possible to ascertain because of some limitations, but the high rate of dental caries definitely portrays poor oral health among them. It is not to be forgotten that oral health is a component of general health and oral health status may be considered to represent the level of health care of a nation. So initiative should be taken to improve the oral health through appropriate measures.

\section{References}

1. Porter S. Oral health sensations associated with illicit drug abuse. British Dental Journal 2005; 198:147.

2. Robinson PG, Acquah S, Gibson B. Drug users: Oral health-related attitudes and behaviors. Br Dent J 2005; 198:219-24.

3. Charnock S, Owen S, Brookes V, Williams M. A community based programme to improve access to dental services for drug users. Br Dent J 2004; 196:385-8.

4. Scheutz F. Dental health in a group of drug addicts attending an addiction-clinic. Community Dent Oral Epidemiol 1984; 12:23-8.

5. Rees TD. Oral effects of drug abuse. Crit Rev Oral Biol Med 1992; 3:163-84.

6. Braunwald E, Fauci AS, Kasper DL, Hauser SL, Longo DL, Jameson JL, editors. Harrissons principle of internal medicine. Alcoholism and drug dependency, Messing RO. 15th ed. McGraw-Hill; 2003. p. 2557.

7. World Drug Report. United Nations Office on Drugs and Crime publication. ; Geneva: 2007. p. 30.

8. Ray R. Extent, Pattern and trends of drug abuse in India. Ministry of social justice and empowerment, Government of India and United Nations office on drugs and crime, Regional office of South Asia. New Delhi: Executive Summary; 2004; 7.

9. World Drug Report. United Nations Office on Drugs and Crime publication. Geneva: 1997; 34-8.

10. Thavarajah R, Rao A, Raman U, Rajasekaran TS, Joshua E, Hemalatha R, et al . Oral lesions of 500 habitual psychoactive substance users in Chennai, India. Arch Oral Biol 2006; 51: 512-9. 